\title{
Linear Growth and Nutritional Status of Young Gabonese Sickle Cell Patients, and Associated Factors
}

\author{
Eliane Kuissi Kamgainga, b, Steeve Minto'o Rogombe ${ }^{\mathrm{a}, \mathrm{c}, \text { e }}$, Julienne Minko ${ }^{\mathrm{a}}$, \\ Carine Eyi Zang ${ }^{\mathrm{a}, \mathrm{c}}$, Ulrich Bisvigou ${ }^{\mathrm{d}}$, Jean Koko ${ }^{\mathrm{a}, \mathrm{c}}$, Simon Ategbo ${ }^{\mathrm{a}, \mathrm{b}}$
}

\begin{abstract}
Background: Stunting and undernutrition mark the nutritional status of the sickle cell patient, but some surveys show trends to overweight in some countries. The primary objective of this study was to compare the growth of children with sickle cell, with non-sickle cell children in Gabon.

Methods: It was a prospective case-control study, conducted from April to June 2016 in Libreville and Lambarene in Gabon. Cases were homozygous (SS) sickle cell children aged from 0 to 15 years; controls were normal hemoglobin-AA documented, matched by sex and age. We compared their weight, height, arm and head circumferences measured according to conventional techniques.

Results: We compared 118 cases to 118 controls, mean age was $85 \pm$ 7.2 months, and the sex ratio was 1.07 . Before 59 months, there was no significant difference in the comparison of the averages of the anthropometric indices except for the z-score of the brachial perimeter for age which was smaller in the cases $(-0.85$ versus $-0.19, \mathrm{P}=0.04)$. The risk of stunting in cases was greater (odds ratio $(\mathrm{OR})=6.9,95 \%$ confidence interval (CI): 5.4 - 8.3), the growth retardation increased with age, correlated factors with growth retardation were male gender $($ relative risk $(\mathrm{RR})=2.04,95 \%$ CI: $1.2-2.7)$, a mother with no remunerative activity $(\mathrm{r}=0.11, \mathrm{P}<0.03)$, a number of transfusions $>$ $3(\mathrm{r}=0.2, \mathrm{P}=0.003)$, and mean hematocrit of 9.6-15.9\% $(\mathrm{r}=0.4, \mathrm{P}<$ $0.004)$. There were no obese subjects in cases.
\end{abstract}

Conclusions: Growth retardation of children suffering from sickle cell in Gabon appears and increases with age. Male gender, low socio-

Manuscript submitted January 8, 2018, accepted February 21, 2018

aDepartment of Pediatrics, Faculty of Medicine, University of Health Sciences, PO Box 4009, Libreville, Gabon

bPediatric Ward, Teaching Hospital of Libreville, PO Box 7061, Libreville, Gabon

'Pediatric Ward, Teaching Hospital of Angondje, PO Box 14696, Libreville, Gabon

${ }^{\mathrm{d}}$ Department of Public Health, Faculty of Medicine, University of Health Sciences, PO Box 4009, Libreville, Gabon

'Corresponding Author: Steeve Minto'o Rogombe, Department of Pediatrics, Faculty of Medicine, University of Health Sciences, PO Box 4009, Libreville, Gabon.Email: steeve.mintoo@hotmail.fr

doi: https://doi.org/10.14740/ijcp290w economic conditions and signs of severity or non-controlled disease are correlated with this retardation.

Keywords: Sickle cell disease; Growth; Associated factors; Gabon

\section{Introduction}

Sickle-cell anemia (SCA) is the first monogenic genetic disorder in the world, affecting nearly $2.5 \%$ of the Gabonese population, with about 800 births of homozygous children each year [1]. Sickle cell life expectancy is currently better in developing countries than it was a few years ago [2-4]. This improvement is attributed in part to earlier diagnosis, systematic antibiotic prophylaxis, improved sickle cell vaccination status, prevention of vascular accidents, hydroxyurea prescription and transfusion programs [5]. SCA is commonly associated with stunted growth or even delayed onset of puberty. Several causes are attributable to these facts, including the chronicity of anemia, the inter-critical management of the disease in our context, but also the socio-demographic factors of the patients. Recent surveys show that sickle cell children are prone to global overweight and obesity, both in developed and developing countries [6,7]. This is dissimilar to a large number of other investigations which highlight the negative consequences of sickle cell disease on the weight and growth of affected individuals $[8,9]$.

The primary objective of our study was to compare the nutritional status and growth of sickle cell aged 0 - 15 years old in Gabon with those of their non-sickle cell fellows. The secondary objective was to determine the factors associated or correlated to the differences observed.

\section{Materials and Methods}

This case-control study took place from April 1 to June 30, 2016, in the cities of Libreville and Lambarene. The cases were homozygous (SS) sickle cell children, aged from 0 to 15 years, drafted from the registers of two public hospitals of the two cities. Controls were documented hemoglobin-AA subjects, recruited from the same schools and pre-school centers, or from the same immunization centers as those attended by 
the cases.

\section{Selection of subjects}

We enlisted sickle cell patients who had been in the pediatric wards of Libreville Teaching Hospital, and the Albert's Schweitzer Hospital in Lambarene during the year 2015, and also sickle-cell diagnosed infants in immunization centers around these hospitals. A random draw was performed to include cases from the constituted list. We listed school and preschools centers were the cases went to. For each SCA children, we randomly selected six children by school-provided lists of classes, or vaccination lists in health centers. We matched by sex and age \pm 1 month for children less than 59 months, \pm 3 months for school-aged. After the parental agreement, the cases were recalled in the non-critical phase, at a distance from any acute pathological event, to collect the socio-demographic, anthropometric data, the medical information of the subject and the realization of a cell blood count (CBC). For the controls who participated in the survey, the parental agreement was also obligatory, and we collected the same data as in the cases, except the CBC. All the children were given medical consultation if necessary. At the end of the data collection, we made a final draw to eliminate controls, so that the matching was built on the ratio of 1 case/ 1 control.

The minimum number of 93 cases was obtained using the Schwartz formula, $\mathrm{n}=\left(\mathrm{t}^{2} \times \mathrm{p}(1-\mathrm{p})\right) / \mathrm{e}^{2}$, where e is significance threshold of $0.05(5 \%), p$ is prevalence and $t$ is $95 \%$ confidence interval (CI)), using chronic malnutrition (assessed with the height for age index (HAZ)) in children in Gabon as 3\% [10].

\section{Conduct of the survey and anthropometric measurements}

Socio-demographic data included the subject's civil status, the number of children living at home, the child's rank in the siblings, the level of education, the occupational activity of the mother and the activity of the head of the family. The medical history collected the basic hemoglobin, the number of transfusion episodes and the number of hospitalizations without transfusions. The anthropometric parameters (weight, height or length, head circumference and mid-upper arm circumference) were collected according to the conventional methods of the WHO by the same examiner. The materials used were: an inextensible tape measure; a $\mathrm{SECA}^{\mathrm{TM}}$ brand electronic baby weighing scales, giving the weight at $10 \mathrm{~g}$; a SECA ${ }^{\mathrm{TM}}$ brand electronic weighing scale giving the weight at $100 \mathrm{~g}$; an infantometer for measuring the prone size in infants giving the size within $0.5 \mathrm{~cm}$; a stadiometer for standing measurement graduated to $0.5 \mathrm{~cm}$. The anthropometric data were managed with WHO ANTHRO ${ }^{\odot}$ and WHO ANTHRO PLUS ${ }^{\complement}$ software, which provides the z-scores for age and gender according to the WHO 2006 growth standards, which are available at http://www.who.int/childgrowth/software/en/. The WHO ANTHRO ${ }^{\odot}$ software calculates z-scores for subjects aged 0 - 59 months: weight for age (WAZ), HAZ, weight for height (WHZ), body mass index (BMI) for age (BAZ), head circumference for age (HCZ) and mid-upper arm circumference for age (MUACZ). WHO ANTHRO PLUS ${ }^{\odot}$ calculates the z-scores of patients aged 60 months and older. WHO uses only three indices for those aged 60 - 120 months: WAZ; HAZ; BAZ; and for children over 120 months of age, WHO uses only HAZ and BAZ indices.

The growth retardation is defined by a $\mathrm{HAZ}<-2$, moderate acute malnutrition is defined by a WHZ or BAZ $<-2$, and severe acute malnutrition is defined by WHZ or BAZ $<-3$. At the end of the anthropometric measurements, only for SCA children, we proceeded aseptically to the collection of $2 \mathrm{~mL}$ of venous blood to realize a complete $\mathrm{CBC}$ with a Coulter SK ${ }^{\mathrm{TM}}$ hematology automaton.

\section{Ethical considerations and parental agreement}

This survey obtained authorization from the Directorate General of Health, as well as that of the Ministry of National Education before it took place. The inclusion of each case or control was subject to parental approval by signature of the informed consent form.

\section{Data management}

The data obtained were managed on EPI INFO 7. (CDC), and exported for a further or a counter-analysis on SPSS 20; the graphs were obtained using EXCEL 2010. Chi-square test was used to assess differences in categorical data between groups. We used Student's $t$-test for comparisons of means. The relationship between SCA and growth or nutritional status was established by calculating the odds ratio (OR). Relative risk (RR) was used to compare a risk factor between the genders. The relationship between stunting in SCA children and risk factors was assessed using Pearson " $r$ " coefficient. A P value $<$ 0.05 was considered significant.

\section{Results}

We retained 118 SCA subjects out of the 131 listed and seen; we matched them to 118 controls. Of the 236 children, there were 114 girls (48.3\%) and 122 boys (51.7\%), with a sex ratio of 1.07 . The sample contained 140 children $(59 \%)$ recruited in Libreville and 96 children (41\%) in Lambarene.

The mean age (in months) of all the children retained was $85.2 \pm 46.8$. The mean age of patients with SCA was $83.6 \pm$ 46.7 months, while that of the controls was $87.3 \pm 47.1$ months $(\mathrm{P}=\mathrm{NS})$.

Children aged less than 60 months accounted for $35.6 \%$ $(\mathrm{n}=84)$, children aged 60 - 119 months accounted for $28 \%$ $(\mathrm{n}=66)$, and those aged 120 months and older accounted for $36.4 \%(\mathrm{n}=86)$.

The mothers of the children were on average $33.8 \pm 7.6$ years old. The educational attainment of the children's mothers was university diploma in $26 \%(\mathrm{n}=61)$, secondary school in $52 \%(\mathrm{n}=123)$ and $22 \%(\mathrm{n}=52)$ primary school or illiterate 
Table 1. Means of z-Scores of Anthropometric Indices of Children Aged 0 - 59 Months Recruited

\begin{tabular}{|c|c|c|c|c|c|}
\hline & \multicolumn{2}{|c|}{ Cases $(n=42)$} & \multicolumn{2}{|c|}{ Controls $(n=42)$} & \multirow{2}{*}{$\mathbf{P}$} \\
\hline & Mean & SD & Mean & SD & \\
\hline WAZ & -0.66 & 0.83 & -0.29 & 1.03 & NS \\
\hline HAZ & -0.16 & 0.76 & 0.06 & 0.98 & NS \\
\hline BAZ & -0.88 & 1.64 & -0.54 & 1.31 & NS \\
\hline WHZ & -0.86 & 1.23 & -0.58 & 1.53 & NS \\
\hline $\mathrm{HCZ}$ & 0.67 & 1.31 & 0.57 & 1.14 & NS \\
\hline MUACZ & -0.85 & 1.45 & -0.19 & 1.07 & 0.04 \\
\hline
\end{tabular}

WAZ: weight for age; HAZ: height for age index; BAZ: body mass index for age; WHZ: weight for height; HCZ: head circumference for age; MUACZ: mid-upper arm circumference for age. P, value of Student's $t$-test.

level. These mothers had a lucrative activity in 55\% $(\mathrm{n}=130)$, $31 \%(n=73)$ were without income sources, and $14 \%(n=33)$ were students.

Among the children, 34\% $(\mathrm{n}=80)$ lived in a single-parent family, and $66 \%(n=156)$ in a couple. The average number of children at home was $4.02 \pm 2$, and the average rank of the children in the siblings was $3 \pm 2.5$.

In $34 \%(n=80)$ the head of family occupational job was Non-executive in the private sector, in $27 \%(\mathrm{n}=64)$ non-executive in public sector, in $18 \%(\mathrm{n}=42)$ independent, in $13 \%(\mathrm{n}$ $=31)$ executive in all sectors and in $8 \%(n=19)$ jobless.

There was no SCA children who received zinc in his usual treatment, neither who had taken hydroxyurea.

The means of the anthropometric parameters of the cases and controls, as well as their comparisons, are reported in Tables 1-3.

We found no SCA children obese, and 2.5\% $(n=3)$ obese in the population control. For growth, the risk of stunting for SCA children compared to controls was OR $=6.9$ (95\% CI: 5.4 - 8.3). For malnutrition, the risk of acute malnutrition (moderate or severe) in SCA compared with a control subject was OR $=2.9$ (95\% CI: 2.3 - 3.5).

The RR of growth retardation in the SCA boys compared to the SCA girls was 2.04 (95\% CI: 1.2 - 2.7), the RR of moderate acute malnutrition in an SCA boys compared to an SCA girls was 1.04 (95\% CI: $0.75-1.3)$.

The factors positively correlating with the growth retardation of the SCA children included are summarized in Table

Table 2. Means of z-Scores of Anthropometric Indices of Children Aged 60 - 119 Months Recruited

\begin{tabular}{lllllll} 
& \multicolumn{2}{c}{ Cases $(\mathbf{n}=\mathbf{3 3})$} & & \multicolumn{2}{c}{ Controls $(\mathbf{n}=\mathbf{3 3})$} & \multirow{2}{*}{ P } \\
\cline { 2 - 3 } \cline { 5 - 6 } & Mean & SD & & Mean & SD & \\
\hline WAZ & -1.41 & 1.2 & & 0.08 & 1.09 & $<0.0001$ \\
HAZ & -0.89 & 1.2 & & 1.11 & 1.18 & $<0.0001$ \\
BAZ & -1.31 & 1.59 & & -0.96 & 1.57 & NS \\
\hline
\end{tabular}

WAZ: weight for age; HAZ: height for age index; BAZ: body mass index for age. $P$, value of Student's $t$-test.
Table 3. Means of z-Scores of Anthropometric Indices of Children Aged $\geq 120$ Months Recruited

\begin{tabular}{lllllll} 
& \multicolumn{2}{c}{ Cases $(\mathbf{n}=\mathbf{4 3})$} & & \multicolumn{2}{c}{ Controls $(\mathbf{n}=\mathbf{4 3})$} & P \\
\cline { 2 - 3 } & Mean & SD & & Mean & SD & \\
\hline HAZ & -1.71 & 1.66 & & -0.06 & 1.32 & 0.0001 \\
BAZ & -2.31 & 0.91 & & -1.23 & 1.02 & 0.014 \\
\hline
\end{tabular}

HAZ: height for age index; BAZ: body mass index for age. P, value of Student's $t$-test.

4.

\section{Discussion}

The anthropometric parameters of this survey show that there is a difference in the means of the two groups. The SCA patient is globally smaller and of lower weight than his non-SCA control for the same age and sex. Nevertheless, the differences observed are peculiar to each age group.

In children younger than 60 months (Table 1), there was no statistical difference. Only the comparison of MUACZ means indicated a significant difference. MUACZ of SCA was smaller than that of controls. This fact underlines the sensitivity of the MUAC in children of this age group. The sensitivity of the brachial perimeter measurement has been demonstrated for a long time by Kanawati and McLaren, and reissued in the WHO 2006 standards for which the brachial perimeter is the necessary measure in mass surveys and food products crisis situations $[11,12]$. A study carried out before the publication of the 2006 WHO growth standards showed that the brachial perimeter of SCA children was significantly smaller than that of controls [13].

For the head circumference, there was no difference in our results between $\mathrm{HCZ}$ of SCA children and HCZ of nonSCA children. This finding was similar to Senbajo et al's study, which led them to conclude that the growth patterns of the cranial perimeter of the general population can be used to monitor the cranial circumference of the sickle cell patient [14].

From 5 years of age (Tables 2 and 3), the Gabonese SCA patient was smaller than the child of the same sex and age

Table 4. Factors Positively Correlating With the Growth Retardation of the SCA Children Included

\begin{tabular}{lll}
\hline & $\mathbf{r}$ & $\mathbf{P}$ \\
\hline Number of children at home $\geq 4$ & 0.27 & 0.02 \\
Single parent family & 0.2 & $\mathrm{NS}$ \\
Mother's education level (none/primary school) & 0.12 & 0.048 \\
Mother without income generating activity & 0.11 & 0.03 \\
Head of the family non-executive & 0.15 & 0.048 \\
Number of transfusions ( $\geq 3$ ) & 0.2 & 0.002 \\
Hemoglobin level between 6 and 7 & 0.06 & $\mathrm{NS}$ \\
Osteo-articular complications & 0.12 & $\mathrm{NS}$ \\
Hematocrit (9.6-15.9\%) & 0.4 & 0.003 \\
\hline
\end{tabular}


without SCA, the average of HAZ scores at that age is lower up to 10 years. With growth, the SCA child becomes smaller and thinner than the rest of the general population. Cox et al had already made the same observation in Tanzania on a cohort of 1,041 children; adolescence is the period when the growth deficit of SCA kids increases [4]. The results of Chawla et al from the USA, as well as Esezobor et al from Nigeria, also conclude that growth retardation in sickle cell disease increases with age $[6,9]$. Growth is the physiological phenomenon that characterizes the child; the SCA child grows in a context of chronic energy malnutrition (permanent low oxygenation of tissues) which is characterized by upset growth. Moreover, this chronic malnutrition has a negative effect on the pubertal phase, depriving children from benefiting from the growth acceleration observed during this period, thus resulting in a widening gap at this age $[4,6]$.

Growth retardation rather than acute malnutrition was the disorder that has the highest risk of being observed in SCA. Lukusa Kazadi et al arrived at the same conclusion as us, finding growth retardation $(\mathrm{HAZ} \leq-2)$ four times higher in SCA than in controls. The risk was lower when weight was considered, with a relative 1.2 higher risk in nmalnurished children [15]. Osei-Yeboah et al had findings similar to ours, observing three times more growth retardation in Ghanaian sickle cell children than in their controls, and a non-significant difference in acute undernutrition [16]. This may result from an adaptation of the metabolism of children with sickle cell child to chronic malnutrition. The SCA child could adapt its weight to the needs necessary, but also adequate to its metabolic capacities. Finally, the low sickle cell weight is compensated by his smaller size, thus giving a lower weight for height or BMI.

Male gender was found in our survey to be associated with a higher risk of stunting. The same risk was also found to be statistically significant in the study of Aminasahun et al from Nigeria, and Lukusa Kazadi in the Democratic Republic of Congo (DRC) $[15,17]$. Cox et al also pointed out that the situation was reversed if girls have more severe episodes, but the reasons why girls have better growth than boys remain uncertain [4].

Risk factors found in the analysis correlating with sickle cell growth retardation (Table 4) can be classified as inherent to the disease (intrinsic), its treatment and progression (number of transfusions and hematocrit) and extrinsic factors (socio-economic factors).

For intrinsic factors, the correlation between multi-transfused status and growth retardation in SCA can be explained by the absence of a transfusion program in our context. In SCA child care protocols, transfusion is carried out in an emergency situation, this condition being established either gradually or quite rapidly in case of hemolysis due to an infectious cause. Our results are similar to those of Lukusa Kazadi et al in the DRC, who found an association among more than three transfusions with growth retardation in sickle cell disease [15]. Low hematocrit was also found to be correlated with poor nutritional status or stunting in SCA in Emmanuelchide et al's studies in Nigeria and Nishkar et al in India $[18,19]$. These authors concluded that this accessible and evaluable parameter is a good indicator and predictor of sickle cell general health status. Furthermore, administration of zinc supplementation to the sickle cell child showed apparent effects on their growth and matura- tion [20]. This supplementation is not available in our regions. The introduction of this supplementation in our country, already in need of zinc for the treatment of diarrhea, would be a simple and effective instrument for the management of the sickle cell in a developing country, such as the use of hydroxyurea [5].

An unfavorable socio-economic context can be correlated with poor nutritional status or growth in SCA. Indeed, our results show that, even within this sickle cell population, unfavorable socio-economic conditions (mother with low educational level, a mother without income-generating activities, a head of family non-executive, large family) are associated with stunting. The authors of the DRC, India and Nigeria come to the same conclusion as we do: the sickle cell child in addition to his pathology also pays tribute to sinister socio-economic factors, like the whole population in which he lives [15, $18,19]$. Only the Animashaun et al's survey in Nigeria in 2011 concluded that low socioeconomic status had an inverse (improving) effect on the nutritional status and hemoglobin level of sickle cell patients [17].

\section{Conculsions}

The results of this case-control study show that growth retardation and the acute malnutrition of the sickle cell children are gradually established. The sickle cell child in his early childhood is similar to his control, but over the years becomes smaller than the non-sickle cell child. Obesity is not observed in SCA children in our country. The risk of stunting is greater than that of acute malnutrition. In sickle cell children, the factors correlating with linear growth retardation were age, male gender and factors reflecting a poorly controlled chronic disease. Unfavorable socio-economic conditions also hamper their anthropometric parameters. WHO 2006 standards are useful and effective tools for screening the nutritional status of SCA patient. Our findings lead us to recommend that the nutritional status of SCA child should be a major concern in from the age of 5 years and onward. The introduction of measures that have shown to be effictive in other countries such as zinc administration, dietary advice, easier access to hydroxyurea and transfusion programs could improve the health status of these young patients and their growth.

\section{Conflict of Interest}

None.

\section{Disclosure}

The authors declare no financial aid, no preliminary communication or publication for this study.

\section{References}

1. Delicat-Loembet LM, Elguero E, Arnathau C, Durand P, 
Ollomo B, Ossari S, Mezui-me-ndong J, et al. Prevalence of the sickle cell trait in Gabon: a nationwide study. Infect Genet Evol. 2014;25:52-56.

2. Koko J, Duffilot D, M'Ba Meyo J, Gahouma D, Kani F. Mortalite des enfants drepanocytaires dans un service de pediatrie en Afrique Centrale. Arch Pediatr. 1998;5:965969.

3. Quinn CT, Rogers ZR, McCavit TL, Buchanan GR. Improved survival of children and adolescents with sickle cell disease. Blood. 2010;115(17):3447-3452.

4. Cox SE, Makani J, Fulford AJ, Komba AN, Soka D, Williams TN, Newton CR, et al. Nutritional status, hospitalization and mortality among patients with sickle cell anemia in Tanzania. Haematologica. 2011;96(7):948-953.

5. Iughetti L, Bigi E, Venturelli D. Novel insights in the management of sickle cell disease in childhood. World J Clin Pediatr. 2016;5(1):25-34.

6. Chawla A, Sprinz PG, Welch J, Heeney M, Usmani N, Pashankar F, Kavanagh P. Weight status of children with sickle cell disease. Pediatrics. 2013;131(4):e1168-1173.

7. Akodu SO, Diaku-Akinwumi IN, Njokanma OF. Obesity - does it occur in Nigerian children with sickle cell anemia. Pediatr Hematol Oncol. 2012;29(4):358-364.

8. Mitchell MJ, Carpenter GJ, Crosby LE, Bishop CT, Hines J, Noll J. Growth status in children and adolescents with sickle cell disease. Pediatr Hematol Oncol. 2009;26(4):202-215.

9. Esezobor CI, Akintan P, Akinsulie A, Temiye E, Adeyemo T. Wasting, and stunting are still prevalent in children with sickle cell anemia in Lagos, Nigeria. Ital J Pediatr. 2016;42:45.

10. UNFPA/Direction Generale de la Statistique (DGS) du Gabon/ICF International. Enquete Demographique et de Sante du Gabon (EDS) 2012. http://gabon.unfpa.org/sites/ default/files/pub-pdf/SR198.pdf. Accessed on 10/07/17.

11. Kanawati AA, McLaren DS. Assessing the growth and nutrition of young children. Trans R Soc Trop Med Hyg. 1968;62(4):569-570.
12. WHO/UNICEF/World Bank Group Joint Child Malnutrition Estimates. Levels and Trend in child malnutrition. Key Findings of the 2016 Edition. Disponible a http:// www.who.int/nutrition/publications/jointchildmalnutrition_2016_estimates.pdf?ua=1, accessed 10/07/17.

13. Oredugba FA, Savage KO. Anthropometric finding in Nigerian children with sickle cell disease. Pediatr Dent. 2002;24(4):321-325.

14. Senbanjo IO, Oshikoya KA, Salisu M, Diaku-Akinwumi IN. Head circumference of children with sickle cell disease in Lagos, Nigeria. Pan Afr Med J. 2016;25:4.

15. Lukusa Kazadi A, Ngiyulu RM, Gini-Ehungu JL, Mbuyi-Muamba JM, Aloni MN. Factors Associated with Growth Retardation in Children Suffering from Sickle Cell Anemia: First Report from Central Africa. Anemia. 2017;2017:7916348.

16. Osei-Yeboah C, Rodrigues O, Enweronu-Laryea C. Nutritional status of children with sickle cell disease at Korle Bu Teaching Hospital, Accra, Ghana. West Afr J Med. 2011;30(4):262-267.

17. Animasahun BA, Temiye EO, Ogunkunle OO, Izuora AN, Njokanma OF. The influence of socioeconomic status on the hemoglobin level and anthropometry of sickle cell anemia patients in steady state at the Lagos University Teaching Hospital. Niger J Clin Pract. 2011;14(4):422427.

18. Emmanuelchide O, Charle O, Uchenna O. Hematological parameters in association with outcomes in sickle cell anemia patients. Indian J Med Sci. 2011;65(9):393-398.

19. Nikhar HS, Meshram SU, Shinde GB. An anthropometric and hematological comparison of sickle cell disease children from rural and urban areas. Indian J Hum Genet. 2012;18(1):40-42.

20. Zemel BS, Kawchak DA, Fung EB, Ohene-Frempong K, Stallings VA. Effect of zinc supplementation on growth and body composition in children with sickle cell disease. Am J Clin Nutr. 2002;75(2):300-307. 